Brit. F. vener. Dis. (1971) 47, 188

\title{
A 'single dose' treatment of gonococcal urethritis with rifampicin
}

\author{
V. L. ONGOM \\ Department of Preventive Medicine, Makerere University Medical School, Uganda
}

Rifampicin (Rifadin), a semisynthetic antibiotic, belongs to the family of rifamycins and is produced by Streptomyces mediterranei. It is known to be effective in the treatment of gonorrhoea, and serum concentrations after a single oral dose of $900 \mathrm{mg}$. have been shown to range from $27.2 \mu \mathrm{g}$. $/ \mathrm{ml}$. at $2 \mathrm{hrs}$ to $1.64 \mu \mathrm{g} . / \mathrm{ml}$. at $24 \mathrm{hrs}$, the latter being in excess of the in vitro minimum inhibitory concentration for the gonococcus (Lepetit Pharmaceuticals, 1968). The drug is well tolerated at this dose. When it was used as 'single dose' therapy by Willcox, Morrison, and Cobbold (1970), there was an 11.2 per cent. failure rate among 89 cases of gonorrhoea in men, a result which compared favourably with those yielded by other types of oral therapy. However, in this series as in most others, there was the usual difficulty in distinguishing treatment failure from reinfection, and the figure thought by these authors to be a more accurate indication of failure was 6.7 per cent.

\section{Present investigations}

In carrying out a trial of this drug it was decided to include a group of patients who could be admitted to hospital for supervision, so as to minimize, if not exclude, the possibility of re-infection. Results in these patients could then be compared with results in out-patients and both could be compared with results of treatment with intramuscular penicillin.

\section{Material}

Only patients with fresh infections, who had received no antibiotics in the previous 2 weeks, were accepted for the trial. The first 43 were men of the Uganda Armed Forces and all were admitted as in-patients to a Military Hospital; the remaining 78 men were civilians seen at the Kasangati Health Centre and treated as out-patients. Diagnosis was based on detection of Gram-negative intracellular diplococci in smears of urethral discharge; cultures were performed in some cases.

Received for publication April 24, 1970
Out of a total of 121 persons who reported at the two centres with gonococcal urethritis, 36 were found to have profuse discharge, 77 moderate discharge, and eight scanty discharge. An incubation period of 1-3 days was given by seventy patients, $4-5$ days by $28,6-7$ days by sixteen, 8-10 days by three, and more than 10 days by four only. The duration of illness before reporting for treatment varied considerably: 1-3 days for 54 patients, 4-5 days for 32, 6-7 days for fifteen, 8-10 days for eleven, and more than 10 days for nine. A previous history of urethritis was denied by 54 patients, but 23 gave a previous history of one episode, twenty of two episodes, six of three episodes, and eight of multiple episodes. The majority of the patients, 106, were in the age group 16-25 yrs, ten were aged between $26-40 \mathrm{yrs}$, and five were above 40 years of age.

\section{Treatment}

On entry to the trial, patients were allocated at random to treatment either by rifampicin or by intramuscular penicillin. Penicillin treatment was by 'Triplopen' 2.5 m.u. (benethamine penicillin $1 \mathrm{~m} . u$., procaine penicillin 0.5 m.u., benzyl penicillin sodium 1 m.u.).

Rifampicin was given in one of two schedules: either a single oral dose of six capsules (total $900 \mathrm{mg}$.) or a single oral dose of eight capsules (total 1,200 mg.); in either event the drug was given under supervision and in the military cases half an hour before the mid-day meal. The inpatients remained in hospital for at least one week; outpatients were seen after 1-3 days, 7 days, and 2, 4 and 8 weeks. The military patients were also re-examined at 4 and 8 weeks. Failure of treatment was diagnosed if there was persistence or recurrence of urethral discharge and gonococci were present in Gram-stained smears.

TABLE I Dosage schedules and results

\begin{tabular}{|c|c|c|c|c|}
\hline \multirow[t]{3}{*}{ Treatment } & \multirow{3}{*}{$\begin{array}{l}\text { Total } \\
\text { cases }\end{array}$} & \multicolumn{3}{|c|}{ Results } \\
\hline & & \multirow[t]{2}{*}{ Cured } & \multicolumn{2}{|c|}{ Failed } \\
\hline & & & No. & Per cent. \\
\hline $\begin{array}{r}\overline{\text { Rifampicin }}(900 \mathrm{mg} .) \\
(1,200 \mathrm{mg} .)\end{array}$ & $\begin{array}{l}27 \\
38\end{array}$ & $\begin{array}{l}25 \\
36\end{array}$ & $\begin{array}{l}2 \\
2\end{array}$ & $\begin{array}{l}7 \cdot 4 \\
5 \cdot 2\end{array}$ \\
\hline$\overline{\text { Triplopen (2.5 m.u.) }}$ & 56 & $\overline{53}$ & 3 & $\overline{5 \cdot 3}$ \\
\hline
\end{tabular}




\section{Results}

Out of a total of 121 patients, 65 were treated with rifampicin and 56 with triplopen. Those treated with rifampicin were given different doses; these are shown in Table I together with the overall results.

All the 43 patients treated at the military hospital had a follow-up of 12 weeks. Of the remaining 78 who were treated at Kasangati Health Centre, ten had 12 weeks' follow-up, 51 had 8 weeks, and the remaining seventeen from 2 to 4 weeks.

There were four cases $(6 \cdot 1$ per cent.) in which treatment with rifampicin failed, and three cases (5.3 per cent.) which failed to respond to triplopen.

Table II shows the results of treatment achieved at the two centres. Whereas only one case $(5 \cdot 2$ per cent.) failed to respond to rifampicin at the military hospital, three cases ( 6.5 per cent.) failed to respond to the same treatment at Kasangati Health Centre. For triplopen, the failure rates at the military hospital and Kasangati were $4 \cdot 1$ and $6 \cdot 2$ per cent. respectively. There were no gastrointestinal side-effects from rifampicin and the red discoloration of the urine was actually appreciated by the patients, some of whom believed it was due to elimination of dead gonococci!

TABLE II Results at the two treatment centres

\begin{tabular}{|c|c|c|c|c|c|}
\hline \multirow{3}{*}{ Centre } & \multirow{3}{*}{ Treatment } & \multicolumn{4}{|c|}{ Results } \\
\hline & & \multirow{2}{*}{$\begin{array}{l}\text { Total } \\
\text { cases }\end{array}$} & \multirow{2}{*}{ Cured } & \multicolumn{2}{|c|}{ Failed } \\
\hline & & & & No. & Percent. \\
\hline \multirow{2}{*}{ Military hospital } & Rifampicin & 19 & 18 & 1 & $5 \cdot 2$ \\
\hline & Triplopen & 24 & 23 & 1 & $4 \cdot 1$ \\
\hline \multirow{2}{*}{$\begin{array}{l}\text { Kasangati Health } \\
\text { Centre }\end{array}$} & Rifampicin & 46 & 43 & 3 & $6 \cdot 5$ \\
\hline & Triplopen & 32 & 30 & 2 & $6 \cdot 2$ \\
\hline
\end{tabular}

\section{Discussion}

The overall failure rate with rifampicin ( $6 \cdot 1$ per cent.) did not differ significantly from that with 'Triplopen' ( 5.3 per cent.). As stated above military patients were admitted to hospital to ensure that there was no opportunity for re-infection; the results showed there was no significant difference between the rates of failure of in-patient and out-patient treatment for both the rifampicin and penicillin groups. On the other hand, it happened that a majority of in-patients had received the larger of the two dose schedules of rifampicin and most out-patients had received the smaller dose. The effect of this is uncertain; the overall results showed that there was no significant difference between the results given by the two schedules, and of 21 gonococcal cultures tested for sensitivity to rifampicin by the disc diffusion method none showed resistance.

The main conclusions from the trial were that rifampicin was as effective as 'Triplopen' 2.5 mega units, and that it was easy to administer and well tolerated. It could be a useful alternative when treatment by penicillin is contraindicated or when there is failure of treatment with penicillin or tetracycline.

\section{Summary}

121 men with gonorrhoea, 43 of them Military Hospital in-patients, underwent treatment as follows: Rifampicin by a single oral dose of $900 \mathrm{mg}$. in 27 cases and 1,200 mg. in 38 cases; 'Triplopen' 2.5 m.u. intramuscularly in 56 cases. The failure rates were $7 \cdot 4,5 \cdot 2$ and $5 \cdot 3$ per cent. respectively. These failure rates did not differ from each other significantly, nor was there any significant difference between the results in out-patients and in-patients. It is concluded that rifampicin is an effective, safe, and easily administered treatment for gonorrhoea but best used when penicillin is contraindicated or ineffective.

I am indebted to the Gruppo Lepetit S.p.A., Kenya Branch (East Africa), for the generous supply of rifampicin(Rifadin) used in these studies. I am grateful to the Commander, Uganda Armed Forces, for permission to publish this paper and for the facilities provided, to Dr. F. J. Bennett for guidance, to $\mathrm{Mr}$. Opio of the Microbiology Unit, Jinja Hospital, without whose assistance the sensitivity tests could not have been carried out, and to Mr. C. Obiro for most of the ward work.

\section{References}

Lepetit Pharmaceuticals (1968) 'Rifampicin-a Handbook'. Slough

Willcox, R. R., MORRISON, G. D., and COBbOLD, R. J. C. (1970) Brit. F. vener. Dis., 46, 145

Traitement de l'urétrite gonococcique avec la rifampicin en dose unique

SOMMAIRE

121 hommes gonococciques, dont 43 étaient hospitalisés dans un hôpital militaire, reçurent le traitement suivant: rifampicin $900 \mathrm{mg}$. en dose orale unique pour 27 cas et $1.200 \mathrm{mg}$. pour 38 cas. Une dose de 2,5 méga-unités de 'Triplopen' a été employée par voie intramusculaire dans 56 cas. Les taux respectifs d'échec furent les suivants: 7,4 pour cent, 5,2 pour cent et 5,3 pour cent. Des taux d'échec ne different pas entre eux d'une manière significative et il n'y eut pas non plus de différence significative dans les résultats chez les malades ambulatoires ou hospitalisés. On conclut que la rifampicin est efficace, sûre, et qu'elle constitue un traitement facile à administrer dans le gonococcie mais qui a son meilleur emploi lorsque pénicilline est contre-indiquée ou inefficace. 